\title{
SUBLIMAÇÃO E PULSÃO DE MORTE: A DESFUSÃO PULSIONAL
}

\author{
Clarissa Metzger
}

Nelson da Silva Junior

Resumo: Com o advento do segundo dualismo pulsional freudiano, surge uma série de mudanças no entendimento da sublimação. Essa passa a se apresentar como a causa por excelência da desfusão das pulsões, o que nos leva a um paradoxo: ao mesmo tempo em que a sublimação é a base da cultura, ela é também causa da destrutividade no seio dessa mesma cultura. A pulsão de morte resultante da desfusão das pulsões, por sua vez, teria consequências tanto em cada indivíduo quanto na cultura como um todo, tal como o que se observa em relação ao primado da imagem na sociedade contemporânea. Este artigo busca discutir alguns dos efeitos da pulsão de morte desfusionada, entendida como resultado da sublimação, principalmente no que tange à sublimação implicada na criação literária.

Palavras-chave: Cultura. Sublimação. Pulsão de morte. Fusão e desfusão pulsional. Criação literária.

As hipóteses freudianas sobre a pulsão de morte e a pulsão de vida começaram a ser seriamente estudadas há relativamente pouco tempo, se pensarmos que foram apresentadas em 1920, com o texto Mais além do Princípio do Prazer. Talvez o nome "pulsão de morte" tenha, por um lado, levantado resistências, como se costuma dizer, mas por outro, certamente convidou a uma leitura criativa do texto, mais orientada pelas ressonâncias míticas do termo que por sua economia conceitual na obra freudiana. Este artigo visa abordar um par de conceitos-chave ligado aos conceitos pulsão de morte e pulsão de vida e ainda menos estudados do que estes, a saber, os 
conceitos de desfusão e fusão pulsional. Usando aqui uma analogia culinária, se as pulsões de vida e de morte fossem os ingredientes de uma receita, a fusão e a desfusão pulsional seriam encontradas na parte seguinte, no "como fazer."De fato, elas correspondem à parte das "regras" de associação entre as pulsões de vida e a pulsão de morte. Contudo, longe do espírito de uma receita, o uso dos conceitos de fusão e de desfusão pulsional é bastante flexível, e, às vezes, contraditório no próprio Freud. Tais variações permitiram leituras e desenvolvimentos diversos na literatura psicanalítica sobre o tema. Pretendemos apresentar tal diversidade, particularmente a partir da questão da sublimação implicada pela criação literária.

\section{Questões preliminares}

Antes de entrarmos na discussão sobre a fusão e desfusão pulsional, é importante contextualizá-las. De fato, esse par de conceitos só tem sentido no que se conhece pela "segunda teoria pulsional" de Freud, apresentada em 1920 no texto" Além do princípio do prazer" (Freud, 1920/1980). Até então, uma pulsão era uma força definida com origem no corpo, que atingiria o psiquismo de um modo que este não pudesse fugir. Com pequenas variações, esta definição - condizente com a ideia de que o funcionamento do psiquismo busca sempre uma diminuição do nível de tensão interna, de acordo com o princípio do prazer - vale para Freud pelo menos até 1920. Nesse ano, no capítulo quinto do texto acima indicado, uma pulsão é redefinida como uma tendência inerente a todo organismo vivo de retorno a uma situação anterior. Esta redefinição permite que Freud avance em um raciocínio ousado, mas que tem a vantagem de poder dar conta de fenômenos psíquicos que claramente desobedeciam ao princípio do prazer. Todavia, o preço da ousadia é a admissão da existência de uma "pulsão de morte." O argumento de Freud é simples: se toda "situação anterior" fosse o objeto de uma tendência de retorno do organismo, haveria dois tipos de pulsões. Em primeiro lugar, o tipo que coagiria o organismo a retornar aos momentos posteriores ao seu nascimento. Em segundo lugar, o tipo que o obrigaria a retornar ao estado anterior à vida orgânica. Esta seria a pulsão de morte.

Naturalmente, uma série de questões surgem daí. Mas vamos deixálas aqui de lado para que possamos entrar logo em nosso tema. Com exceção de uma, que justamente nos leva diretamente ao problema da fusão e da desfusão pulsional: aquela de como a vida é possível com tal pulsão de morte. A resposta de Freud é que a vida só existe porque a pulsão de morte se associa, se funde, com as pulsões de vida.

\section{Sublimação e desfusão}

O termo "desfusão" aparece pela primeira vez na obra freudiana em 1922, em Dois verbetes de enciclopédia. A teoria da libido: 
As pulsões eróticas e as de morte estariam em misturas, fusões regulares; mas "desfusões" também estariam sujeitas a ocorrer. A vida consistiria nas manifestações do conflito ou da interação entre as duas classes de pulsões. A morte significaria para o indivíduo a vitória das pulsões destrutivas mas a reprodução representaria para ele a vitória de Eros. (Freud, 1923a/1980, p. 312)

Contudo, só encontramos uma discussão mais extensa sobre a desfusão pulsional em 1923, no artigo "O ego e o id" (Freud, S., 1923b/1980), em que Freud afirma que toda sublimação se efetua por meio da mediação do eu, que começa por transformar a libido objetal sexual em narcísica e, depois, talvez, passa a fornecer-lhe outro objetivo. Em verdade, surge aqui uma questão que nos ocupará de modo central e que merece consideração cuidadosa, a de saber se este não será o efeito de toda e qualquer sublimação. Posteriormente, diz Freud, "teremos de averiguar se esta transformação não pode ter como consequência outros destinos pulsionais; se, por exemplo, ela não pode ocasionar uma desfusão das diversas pulsões que se acham fundidas entre si." (Freud, 1923b/1980, p. 44, itálicos nossos).

Com efeito, a transformação de libido objetal em libido narcísica implicaria uma dessexualização; a questão introduzida e posteriormente desenvolvida por Freud é que,a partir de tal transformação, também ocorre algo como um novo destino pulsional, isto é, a desfusão das pulsões. Ora, mas, afinal, qual seria o problema da desfusão pulsional?

A resposta a essa questão é bem complexa. Para resumir uma série de reflexões presentes em alguns textos de Freud ${ }^{1}$, a desfusão pulsional separaria as pulsões de vida e de morte no que diz respeito aos fins pulsionais, deixando a pulsão de morte agir livremente dentro e fora do indivíduo, de acordo com sua tendência, promovendo a ambivalência em um espaço em que ela não existia e eventualmente gerando novas fusões, que podem ser particularmente nefastas, entre as estruturas intra-psíquicas. De um modo geral, a desfusão pulsional seria a causa de expressões do "mal pelo mal" no homem, e a eventual fusão pulsional dela decorrente erotizaria a destruição como um fim em si mesmo.

Retornemos agora à questão da relação entre sublimação e desfusão pulsional. A desfusão pulsional seria um derivado tanto da simples dessexualização quanto da sublimação, na medida em que a primeira é uma implicação da segunda ${ }^{2}$. Dentro dessa lógica, chegamos a duas consequências. Em primeiro lugar, o mesmo processo que funciona como base para

1 Fundamentalmente, nos capítulos 4 e 5 de "O ego e o id" (1923b/1980) e em "O problema econômico do masoquismo" (1924/1980). camente como sinônimos, há diferenças entre ambas. De qualquer forma, esta imprecisão deixa de existir a partir da definição final da sublimação, que inclui os três elementos seguintes: a mudança de objeto, de meta e a valorização social (Freud, 1923a/1980). 
a produção da cultura, também produz aquilo que lhe é potencialmente destrutivo.

Ora, se a cultura só se constrói a partir da sublimação,então poderíamos conceber uma desfusão pulsional constitutiva do próprio processo de culturalização humana. Em outros termos, quanto mais sublimação, tanto mais destrutiva a pulsão de morte em uma cultura (Silva Junior, 2001, p. 36, itálicos nossos)

Encontramos aqui um importante paradoxo da sublimação: se é ela que produz a cultura, também é ela que provoca a desfusão pulsional que terá efeitos destrutivos sobre essa mesma cultura. Consequentemente, os efeitos desse tipo de desfusão pulsional se fazem sentir na cultura, uma vez que a ação desses indivíduos quando retorna em direção à cultura deverá traduzir de algum modo os efeitos da pulsão de morte desfusionada no interior de cada um. Mais precisamente, podemos concluir que a cultura deverá sentir tais efeitos pela via do adoecimento de seus membros.

Nesse sentido, poderíamos pensar naqueles que se isolam progressivamente, melancolizados: aqui, os efeitos da pulsão de morte na cultura se fariam sentir pela ausência e isolamento, como o que é comum hoje nas metrópoles, por exemplo. Outros possíveis efeitos da desfusão são possíveis, principalmente relacionados ao primado da imagem na sociedade contemporânea (Silva Junior, 2003).

A segunda consequência que podemos deduzir a partir da sublimação, ligada à primeira, mas diferente dela, seria que a atividade criativa, além de permitir o compartilhamento de produções artísticas singulares, inscrevendo o indivíduo na civilização e além de contribuir para a ligação da pulsão pela via da criação, teria como uma de suas consequências a desfusão e a liberação de pulsão de morte dentro do indivíduo.

Agora nos deteremos mais especificamente nas consequências que isso pode ter para o próprio indivíduo, não mais diretamente para a sociedade em que ele está inserido.

\section{Efeitos nefastos da sublimação}

Poucos autores se debruçaram de forma mais específica e sistemática sobre os efeitos mortíferos da sublimação (Carvalho 1997, 2001; Silva Junior, 1995, 2003, 2006, 2010). Carvalho $(1997,2001)$ se detém nas consequências, por vezes mortíferas, da sublimação na escrita, enquanto Silva Junior $(2003,2006,2010)$ estuda os efeitos da sublimação na sociedade, efeitos estes ligados ao domínio que a pulsão de morte adquire sobre o eu, a partir do processo sublimatório e da consequente desfusão pulsional.

Carvalho (2001) chama nossa atenção para os escritores suicidas, para a possibilidade da ação da pulsão de morte na "desmetaforização" da escrita na poesia de Sylvia Plath e para seus possíveis efeitos mortíferos: a escri- 
ta, atividade sublimatória, poderia, portanto, permitir a livre ação da pulsão de morte pós-sublimação. A autora recorre à segunda teoria freudiana das pulsões, colocando em relevo a pulsão de morte em estado puro, presente na melancolia, por exemplo ${ }^{3}$. Resgatando Birman, ao falar do negativo presente na pulsão de morte, diz que, "operando fundamentalmente em silêncio e sem se restringir aos poderes da agressão destrutiva, a pulsão de morte é o que não quer ser escrito ou falado, sendo, portanto obstáculo à emergência da palavra." (Birman, 1989 citado por Carvalho, 2001, p. 274). Nesse sentido, a hipótese de Carvalho, diversa, mas aparentada à nossa, parece ser de que a pulsão de morte é o que impede que a escrita se dê de modo pleno. Entendemos, em uma inversão desse raciocínio, que a atuação da pulsão de morte pode ser entendida também como consequência da própria escrita enquanto processo criativo/sublimatório, já que tal processo originaria a desfusão pulsional. Assim, parece possível concluir que se por um lado a pulsão de morte é obstáculo para a escrita, por outro lado a própria escrita origina a pulsão de morte que provoca ações de desligamento dentro do indivíduo. Ou seja, se a escrita é processo de ligação e se constitui por meio da articulação de ideias e palavras, sua contrapartida anda sempre à espreita.

Silva Junior (2003) aponta para o quanto a sociedade moderna, dominada pela imagem, que se transforma em objeto de desejo, em mercadoria a ser consumida - e, portanto, em objeto pulsional superinvestido - favorece a desfusão pulsional. A ênfase no olhar em detrimento de outros sentidos, como o olfato e o tato, implica em renúncia pulsional desses últimos e em sublimação, que tem como um de seus resultados necessários a desfusão.

Mas, mais do que isso, a identificação com a imagem de um determinado produto, estimulada via produção do comportamento de consumo, substituiria o investimento de libido nos objetos. Assim, a satisfação objetal seria substituída, na sociedade contemporânea, por formas de satisfação narcísicas, via imagem. (Silva Junior, 2006). A satisfação pulsional se daria no interior do indivíduo, causando desfusão das pulsões - lembremos que a identificação, implicada no consumo de uma determinada imagem, é um fenômeno para o qual é imprescindível a dessexualização. Não podemos esquecer que a identificação também pode ser uma das causas da desfusão. Finalmente, a partir de 1923, a sublimação será o evento desfusionante por excelência (Silva Junior, 2001)."A primeira conclusão importante sobre a nova abordagem da sublimação [a partir de 1923] é o fato desta implicar sempre (grifo do autor) uma dessexualização e, portanto, uma desfusão pulsional." (Silva Junior, 2003, p. 36).

A pergunta decorrente do raciocínio acima seria sobre as manifestações dessa desfusão, ao que o próprio autor responde com o exemplo do

3 Embora a autora enfatize que não tem intenção de diagnosticar a autora como melancólica a partir de sua escrita. 
mundo virtual propiciado pela tecnologia atual e com exemplos clínicos nos quais a imagem tem um papel central e surge, ao mesmo tempo, claramente articulada à ação da pulsão de morte (Silva Junior, 2003).

Também é importante atentar para o fato de que o que pode causar a desfusão pulsional, após Além do princípio de prazer (Freud, 1920/1980), é o traumatismo, seja ele advindo do mundo externo, seja o traumatismo constitutivo causado pelo excesso pulsional constitutivo do indivíduo, como o entendemos após a segunda teoria pulsional. Após o "Ego e o id" (Freud, 1923b/1980), no entanto, é a sublimação a grande causa da desfusão (Silva Junior, 2003, p. 36). Assim, chegamos ao potencial destrutivo da sublimação, na forma da desfusão pulsional.

Mas, após a desfusão, o indivíduo ficaria apassivado, diante do crescente desamparo que a desfusão geraria? Não é o que parece. O indivíduo empreenderia tentativas de refusão pulsional, como forma de combater a desfusão e o desamparo gerado por ela. Entretanto, também na tentativa de refusão haveria um risco para o indivíduo.

Na elaboração de uma segunda concepção de sintoma na obra freudiana, no bojo da segunda tópica e da segunda teoria pulsional, apontase as psicopatologias pós-modernas como resultado tanto de desfusões quanto de refusões pulsionais. O masoquismo moral, consequência da violência implacável do supereu em direção ao eu, seria exatamente uma dessas tentativas, das quais seria uma das consequências patológicas mais temíveis. Mas haveria uma diferença entre a desfusão originária do recalque e a desfusão causada pelo imperativo do gozo da sociedade de consumo contemporânea. Enquanto a primeira estaria ligada ao masoquismo moral, no qual um supereu sádico ataca um eu masoquista, a segunda, originada na satisfação narcísica, se organizaria em torno do masoquismo erógeno. Aqui, a destruição do corpo causaria prazer, além de poupar ao indivíduo a culpa resultante do masoquismo moral (Silva Junior, 2006, 2010).

\section{Criação e desfusão}

Carvalho (2001) refere-se a essa pulsão de morte no indivíduo ao dizer que o compartilhamento possibilitado pela criação não livra o indivíduo do sofrimento. Se por um lado criar e fazer alguma produção cultural circular socialmente, tornando-a reconhecida, são operações que permitem uma espécie de apaziguamento do sofrimento, por outro lado, tornase possível supor que a criação em si produziria também algo da ordem da pulsão de morte desfusionada.

Caberia aqui a pergunta se a criação pode efetivamente permitir que o indivíduo lide de algum modo com o excesso pulsional, uma vez que ele continua exposto à pulsão de morte. Assim, a criação - pensemos aqui na escrita - permitiria a ligação de um certo excesso pulsional, talvez antes sem representação, mas acarretaria, por sua vez, uma desfusão ainda 
maior, resultado do processo sublimatório (a escrita entendida aqui como sublimação) e liberadora de pulsão de morte livre. Em outras palavras, se a criação protege contra o excesso, deixa ao mesmo tempo livre a pulsão de morte antes fusionada. Uma vez ocorrida a sublimação, as pulsões de vida seriam sublimadas e as pulsões de morte permaneceriam no indivíduo, silenciosas, porém ativas.

Apoderando-se assim da libido dos investimentos do objeto, erigindo-se em objeto amoroso único, e dessexualizando ou sublimando a libido do isso, o eu está trabalhando em oposição aos objetivos de Eros e colocando-se a serviço de impulsos pulsionais opostos (Freud, 1923b/1980, p. 46, itálicos nossos).

Note-se que Freud afirma que a sublimação teria como resultado que a pulsão de morte obtivesse certo controle sobre o eu. Chegamos ao principal limite da sublimação decorrente da segunda teoria pulsional freudiana: a sublimação, diferente do que pode parecer à primeira vista, favoreceria o domínio da pulsão de morte. É interessante notar )que a direção apontada por Freud aqui nos mostra os efeitos indesejáveis da sublimação no segundo dualismo. Paradoxalmente, o destino pulsional que erige a cultura e proporciona algum alívio para o sofrimento (cf. Freud, 1930/1980) é o mesmo que contribuirá para a destruição dessa mesma cultura e para aumentar o desamparo do indivíduo.

Ora, se considerarmos a hipótese de que quanto mais sublimação, tanto mais pulsão de morte desfusionada, a conclusão lógica é que, sendo a escrita um processo sublimatório, ela tem como consequência a desfusão pulsional. Configurando-se como tentativa de dar conta do desamparo, a escrita corre o risco de gerar ainda mais desamparo do indivíduo frente às suas pulsões. No entanto, se a sublimação acarreta como consequência inevitável a desfusão pulsional, por outro lado, ainda assim essa talvez seja uma das saídas mais eficientes que temos à disposição no enfrentamento do desamparo. Com efeito, se não acaba com o sofrimento, a atividade criativa permite, como diz Carvalho (2001), um "apaziguamento".

\section{Criação e erotização}

Encontramos textos de outros psicanalistas estudiosos da sublimação ou de temas afins que ressaltam, em diferentes articulações, a criatividade envolvida na sublimação, assim como outros aspectos benéficos, com ênfase na erotização (Birman, 1996, 1997, 1999; Castiel, 2007; Kupermann, 2003).

Kupermann (2003) tem como hipótese que a metapsicologia do humor poderia se oferecer como paradigma para o entendimento da criação sublimatória. Partindo de tal hipótese, o autor destaca o aspecto erotizante da sublimação. Assim, desde que exercida a partir de uma identificação 
com o pai que iria apenas até certo ponto (não se tratando, portanto, de uma identificação maciça), o humor ofereceria instrumentos para a noção de "identificação sublimatória", que "incita o indivíduo à experiência de desterritorialização egoica e ao enriquecimento erótico de sua existência." (p. 28). A criação também aparece como resposta frente à experiência do vazio. Segundo o autor,"esse é exatamente o sentido que o conceito de sublimação viria a adquirir na obra de Freud" (p. 109) e complementa:"e, portanto, em última instância, ao movimento pulsional criativo de invenção de novos objetos de satisfação erótica que Freud nomeia, em sua obra, sublimação" (p. 119). A desfusão pulsional e seus possíveis efeitos comparecem no texto do autor, mas a discussão em torno desses temas não se prolonga: o que ganha destaque é a vertente da sublimação como potência erótica criativa.

Birman (1999) refere-se ao indivíduo submetido ao desamparo e à feminilidade - portanto, o indivíduo freudiano depois da enunciação da pulsão de morte - como aquele que pode criar via sublimação, por meio de "uma forma singular de existência e de um estilo próprio para habitar seu ser". (p. 45). A saída para o desamparo seria o constante desejar, a invenção de um estilo, ao invés do tamponamento do desamparo via ideais fálicos - como ocorreria no masoquismo, por exemplo (Birman, 1996). A autoria imprimiria uma marca no real; a sublimação seria a possibilidade de agenciamento do estilo ligado a esta autoria (Birman, 1997, p. 98). Para esse autor, no entanto, o segundo dualismo pulsional daria margem para o entendimento de que, não havendo mais oposição entre sexualidade e sublimação (Birman também concorda com Castiel e Kupermann quanto ao estatuto de dessexualização da sublimação no primeiro dualismo) ${ }^{4}$, a sublimação seria "a transformação da pulsão de morte em pulsão sexual, de maneira que o erotismo e o trabalho de criação se tornariam possíveis" (Birman, 1997, p. 131). Se não é possível "curar" o desamparo, ao menos é possível geri-lo; nessa versão da sublimação no segundo dualismo, ela não seria a verticalização, no sentido da espiritualização, mas sim “lateralização, com o indivíduo não se desprendendo de seu registro corpóreo." (p. 132). Ao invés disso, de modo horizontal, a sublimação permitira a criação de laço social.

Castiel (2007) fala da sublimação no segundo dualismo como auxiliar na conservação da vida, uma vez que se refere a uma manifestação da sexualidade, mesmo que o desamparo permaneça como fundamento da vida. A autora menciona a mudança do primeiro dualismo no qual imperava a restrição à sexualidade, para o desamparo que determina uma satisfação pulsional sempre parcial. No entanto, a ênfase permanece na sublimação

4 Esses autores entendem que no primeiro dualismo pulsional a oposição proposta por Freud entre sublimação e satisfação direta da pulsão sexual colocaria em polos opostos sexualidade e sublimação, sendo que a sublimação seria o equivalente à dessexualização. 
como manifestação de Eros, que permite a presença do desejo como impulso para a criação, assim como encontramos em Kupermann e Birman.

Assim, se não deixam de lado as consequências menos eróticas e criativas da sublimação no segundo dualismo pulsional, sua ênfase está em discutir seus efeitos benéficos. Base para a abordagem escolhida pelos autores acima citados não falta, já que o próprio Freud admite que a pulsão destrutiva pode ser um motor para a mudança. No entanto, nossa intenção neste artigo é discutir os efeitos mais silenciosos da sublimação, naquilo que tange à desfusão pulsional.

\section{0 pessimismo de Freud abre exceções para a Princesa Marie Bonaparte...}

O caráter inexorável da desfusão pulsional e de seus efeitos destrutivos enquanto consequências da sublimação pode, contudo, ser interrogado a partir do trecho de uma carta à Marie Bonaparte:

A "sublimação"é um conceito que contém um juízo de valor. Na verdade significa a aplicação a outro campo em que são possíveis realizações socialmente mais valiosas. Deve-se então admitir que desvios semelhantes do objetivo de destruição e exploração para outras realizações são demonstráveis em ampla escala no tocante a pulsão de morte. Todas as atividades que reorganizam ou efetuam mudanças são em certa medida destruidoras e assim desviam uma porção da pulsão de seu objetivo destruidor original. Mesmo a pulsão sexual, como sabemos, não pode atuar sem alguma medida de agressividade. Portanto, na combinação regular das duas pulsões há uma sublimação parcial da pulsão de destruição. Pode-se por fim considerar a curiosidade, o impulso de investigar, como uma completa sublimação da pulsão agressiva ou destruidora. (Freud, 1937, citado por Jones, 1989, pp. 449-450, itálicos nossos)

Encontramos aqui duas ideias bastante importantes, dado seu caráter de exceção frente ao restante da obra freudiana: primeiro, o aspecto criativo e transformador característico da pulsão de morte parece ficar em evidência nesse trecho da carta. Segundo, a ideia de que seria possível $a$ sublimação da pulsão de destruição. Assim, duas situações seriam possíveis: uma sublimação parcial, no caso da pulsão de morte combinada à pulsão de vida, e uma sublimação completa da pulsão agressiva ou destruidora a partir do impulso de investigação.

Desse modo, haveria a possibilidade de sublimação da pulsão de destruição, possibilidade esta que não encontramos enunciada em nenhum dos textos freudianos publicados. Note-se que, mesmo aqui, essa ideia carece de justificativa teórica. A contradição de Freud com ele mesmo nesse ponto parece notória. Por exemplo, em "O problema econômico do masoquismo" (Freud, 1924/1980), a definição de masoquismo originário 
repousa na ideia de que uma parcela da pulsão de morte nunca chega a ser desviada para o exterior. No "O ego e o id" (Freud, 1923b/1980), por sua vez, Freud afirma que haveria uma parcela das pulsões que nunca seria fusionada. Ambas as afirmações parecem incompatíveis com a ideia de uma sublimação completa da pulsão de destruição.

Tais contradições nos servem aqui como uma autorização ao progresso nesse tipo de investigação. Assim, cabe perguntar, por exemplo, se a atividade artística, tal como a atividade investigativa, também possibilitaria uma sublimação deste tipo, isto é, uma sublimação total, ou se haveria neste caso uma parte da pulsão de destruição que não seria sublimável por esta via, tal como sugere a maioria das afirmações publicadas por Freud sobre o assunto.

O ponto de vista de que a sublimação completa da pulsão de destruição seria possível pela via da atividade investigativa, parece nos autorizar supor que a atividade criativa também possibilitaria a sublimação completa da pulsão de destruição desde que envolvesse, como ocorre na investigação, a pulsão de domínio, que nada mais é do que uma modificação da pulsão de agressão. Mas teríamos aqui um novo problema:como distinguir a criação da investigação? Se ambas dependem dos mesmos processos intra-psíquicos, qual sua diferença?

\section{Pulsão de morte e pulsão de destruição, dois conceitos.}

Retomemos nossos pontos de partida. A possibilidade de sublimação completa da pulsão de destruição surge na carta de Freud como ligada à investigação. Por outro lado, em relação à pulsão sexual regularmente misturada à pulsão de agressão ou de destruição, a sublimação seria apenas parcial. Já em relação à pulsão de morte que não seria desviada para o exterior, ela permaneceria seja desfusionada - e, nesse caso, seus efeitos seriam difíceis de ser identificados, já que sua ação seria silenciosa -, seja fusionada com as pulsões de vida, o que constituiria o masoquismo originário. Embasam esses pontos de vista textos como "O ego e o id" (Freud, 1923b/1980) e "O problema econômico do masoquismo" (Freud, 1924/1980) e "O mal-estar na civilização" (Freud, 1930/1980).

É pouco comum encontrar referências aos efeitos não benéficos da sublimação que, assim como os efeitos criativos, também são de algum modo demonstrados por Freud. A desfusão pulsional é talvez o principal destes efeitos. A dessexualização inerente à constituição do supereu libera pulsão de morte, agora desligada para o interior do indivíduo, mas também para o exterior, em forma de pulsão de destruição.

Freud, mesmo ainda no registro da primeira teoria pulsional, já dava mostras de não acreditar que todo o problema da limitação da sublimação residisse no antagonismo pulsão x cultura, ou seja, no quanto é possível sublimar e no quanto é necessária uma satisfação direta das pulsões. Agora é 
possível compreender que esse é apenas um dos limites da sublimação - e talvez não seja o mais importante deles.

Na carta a Marie Bonaparte, citada acima, Freud parece oferecer uma visão benéfica da sublimação, no sentido de um processo possibilitador da criação e da transformação. Mais do que isso, sugere a ideia de que também é possível ocorrer algo como uma sublimação completa da pulsão de destruição, ao menos quando está presente o impulso investigativo.

É a partir do reconhecimento de uma agressividade inerente ao homem, realizado em "O mal-estar na civilização" (Freud, 1980/1930), que Freud se interrogará sobre o quanto tal observação pode contribuir para alterações na teoria psicanalítica das pulsões. Nesse trabalho, a atividade da pulsão de morte é examinada na medida em que é dirigida para fora do indivíduo como pulsão destrutiva. Freud retoma aqui o argumento já presente em o "Além do princípio do prazer" (Freud, 1920/1980) e em "O problema econômico do masoquismo" (Freud, 1924/1980) a saber, que a agressividade oriunda da pulsão de morte poderia ser utilizada em função da pulsão de vida. Para tanto, ela deve ser orientada para fora do indivíduo, preservando-o, portanto, da destruição.

Ainda que a pulsão de vida e pulsão de morte pareçam sempre trabalhar em direções opostas, na verdade nunca ou raramente aparecem separadamente, mesmo que não haja clareza de como se fundem e se misturam (Freud, 1923b/1980, p. 56). De forma geral, encontram-se fusionadas em diferentes proporções e em lugares diferentes dos originários, e isso dificulta a identificação de cada uma delas em cada momento. (Freud, 1930/1980, pp. 141-142).

Freud insiste que tanto o masoquismo quanto o sadismo implicam uma agressividade mesclada a pulsões eróticas. Admite, portanto, que uma tendência do homem à crueldade e à destrutividade mescla-se à pulsão de vida, constituindo, a partir de variações nas proporções e nos lugares de refusão, tanto os fenômenos normais quanto os patológicos. Com efeito, na metodologia psicopatológica presente nas construções teóricas freudianas, a normalidade e a patologia seriam expressões de um mesmo princípio de organização. Assim, normal e patológico teriam entre si relações de continuidade. Na metodologia psicopatológica,"normal" e "patológico" não são conceitos absolutos, isto é, referentes às "coisas em si".Em tal método, a normalidade é essencialmente desconhecida e a patologia vale como o fenômeno extremo cujo parentesco com a normalidade permite a construção de hipóteses sobre esta última. No caso da agressividade oriunda da pulsão de morte, não se deve supor, portanto, que Freud a considerasse a origem do"mal."Pelo contrário, há inúmeras indicações que a saúde, ou que os "comportamentos e reações saudáveis", por assim dizer, dependem tanto da contribuição da pulsão de morte quanto das de vida. Por negligência deste princípio do método psicopatológico, base hegemônica do pensa- 
mento freudiano, a compreensão da pulsão de morte sempre encontrou e continua encontrando resistências, mesmo no meio psicanalítico. ${ }^{5}$

Isso redimensiona a afirmação de Freud de que a pulsão de morte só pode ser identificada com clareza caso esteja ligada a Eros; pois, no caso contrário, sua manifestação continuaria silenciosa e dificilmente identificável. A ligação com Eros possibilita a descarga da pulsão de morte, direcionando-a para fora do indivíduo. Ainda assim, uma parte da pulsão de morte permanece sempre no próprio indivíduo ao invés de sofrer expulsão. Essa parcela, ao ser refusionada com Eros, constitui o masoquismo originário. Contudo, uma vez desviada para o exterior e fusionada à pulsão de vida, a suposição freudiana é que ela possa ser totalmente sublimada via curiosidade investigativa. Vejamos, contudo, uma dificuldade estrutural desta possibilidade de sublimação total da pulsão de destruição no caso da criação literária.

\title{
8 A periculosidade da sublimação na melancolia e na escrita literária
}

\author{
"de tanto me escrever, me destruí" \\ Bernardo Soares, O Livro do Desassossego
}

Do ponto de vista da cultura, é fácil entender que a desfusão pulsional seria uma consequência inevitável. Com efeito, a formação do supereu, parte inerente da constituição psíquica do homem civilizado, exigiria necessariamente uma sublimação das pulsões. Diz Freud:

Após a sublimação, o componente erótico não mais tem a força para unir a totalidade da destrutividade que com ele se achava combinada, e esta é liberada sob a forma de uma inclinação à agressão e à destruição. Essa desfusão seria a fonte do caráter geral de severidade apresentada pelo ideal - o seu ditatorial "dever ser".(Freud, 1923b/1980, p. 71)

A conclusão é inevitável: a sublimação necessária para a formação do supereu, o qual é por sua vez condição da cultura, provoca simultaneamente a desfusão pulsional e, portanto, a liberação de pulsões agressivas. A sublimação é a causa indireta da desfusão; a origem d'o mal estar na civilização é nada mais nada menos que a própria civilização. Entre os possíveis efeitos desta desfusão pulsional, ela acabaria por expor o próprio eu aos ataques do supereu, colocando em risco sua própria existência. Nesse caso, o exemplo clínico princeps da "cultura pura da pulsão de morte" seria a melancolia, na qual o sadismo do supereu se volta contra o eu do indivíduo (Freud,

5 Mesmo seguidores de Freud, como Jones e Fenichel, reagiram contrariamente à concepção freudiana de pulsão de morte (cf Monzani, 1989, p. 147). 
1917/1980, p. 280). A melancolia pode ser tomada como paradigmática dessa agressividade voltada para o eu, presente nas neuroses narcísicas ou psicoses de modo geral. Mas ainda estamos perdidos sobre o que pensar sobre a sublimação total da pulsão de destruição na criação. Em que seria esta mais perigosa do que outras formas de sublimação? Não seria a escrita literária uma forma específica da sublimação, forma particularmente próxima da desfusão pulsional melancólica? Em seu artigo de 1925, A negação, Freud argumenta em uma direção que permite tal especulação:

A afirmação - como um substituto da união - pertence a Eros; a negativa - o sucessor da expulsão - pertence à pulsão de destruição. O desejo geral de negar, o negativismo que é apresentado por alguns psicóticos, deve provavelmente ser encarado como sinal de uma desfusão pulsional efetuada através de uma retirada dos componentes libidinais. (Freud, 1925/1980, p. 300; itálicos nossos)

As psicoses e as chamadas neuroses graves (dentre as quais devemos incluir as neuroses com características mais narcísicas, frequentemente nomeadas como toxicomanias e transtornos de personalidade borderline, por exemplo) se apresentam como portadoras clássicas de formas compulsivas de negação - que seria manifestação da desfusão. Tome-se como exemplo a negação do laço social por parte do psicótico ${ }^{6}$ ou mesmo a negação que podemos supor presente em indivíduos que sistematicamente se colocam em situações geradoras de grande sofrimento, em um tipo de situação que Freud chama "compulsão de destino"; a constante negação de certas percepções e entendimentos certamente fomentam a repetição de situações que fazem com que o indivíduo "sabote" a si mesmo (Freud, 1920/1980, p. 35).

A escrita literária parece exigir do sujeito um grande esforço de abstração. Seu "material de trabalho" é particularmente abstrato, isto é, afastado de suportes empíricos, se comparado às outras artes, como música, dança, pintura e teatro, por exemplo. Esse material, particularmente na poesia do século XX, é o próprio "eu" do escritor, que deve ser tomado "como um objeto".Talvez, esta exigência de uma extrema renúncia erótica, associada ao reinvestimento maciço na palavra como representação-coisa, isto é, um tipo de reinvestimento do Eu fundado na libido narcísica sejam particulares à metapsicologia da criação literária. Tal metapsicologia é, sem dúvida, próxima àquela da melancolia. A desfusão pulsional inerente a este tipo sublimação, desabilitaria, nesse caso, o psiquismo para uma refusão completa da pulsão de vida com a pulsão de destruição, como no caso aventado por Freud na carta à Marie Bonaparte da investigação. Pelo contrário, em tal situação de cultura pura da pulsão de morte, o funcionamento da palavra enquanto representação-coisa poderia levar o desejo de negação

6 Seria importante discutir a origem dessa negação, e mesmo se se trata somente de negação, o que não é o caso. Mas tal discussão fugiria muito do escopo do presente trabalho. 
ao seu extremo, isto é, à concretização suprema do 'não' no ato do suicídio, tal como encontramos na biografia de alguns poetas e escritores com intensa produção literária. Aqui temos uma hipótese metapsicológica do que pode estar em jogo em casos como esses.

\section{Sublimation and death drive: pulsional defusion}

Abstract: The introduction of Freud's second drive dualism is conected to a series of changes in the understanding of sublimation. Sublimation begins to present itself as the main cause of drive defusion, what leads to a paradox: for, if sublimation is the foundation of culture, it is also the cause of destructivity in this same culture. The death drive resulting from drive defusion has effects as much in each individual - as it is the case of social isolation and melancholy - as in the culture as a whole, as it is observed regarding to the primacy of image in contemporary society. This article aims to discuss some of the effects of defusionned death drive, understood as result of sublimation, mainly in respect to sublimation implied in literary creation.

Keywords: Culture. Sublimation. Death drive. Drive fusion and defusion. Literary creation.

\section{Sublimation et pulsion de mort: La déliaison pulsionnelle}

Resumé: L'avènement du seconde dualisme pulsionnel freudienne entraîne une serie de changements à la comprehension de la sublimation. Celle-ci se presente alors comme la cause par excellence de la déliaison des pulsions, ce qui nous conduit à un paradoxe :si la sublimation est la base de la culture, elle est aussi la cause de la destructivité au sein de cette même culture. La pulsion de mort résultante de la déliaison des puslions, à son tour, aurait des conséquences aussi bien pour l'individu que pour la culture dans son ensemble, tel qu'on s'observe en rapport à la primauté de l'image dans la société contemporaine. Cet article vise discuter quelques uns des effets de la pulsion de mort deliée, comprise comme le résultat de la sublimation, surtout en ce qui concerne la sublimation impliquée dans la création litteraire

Mots-clés: Culture. Sublimation. Pulsion de mort. Liaison et déliaison pulsionnele. Création litteraire

\section{Sublimación y pulsión de muerte: la desfusión pulsional}

Resumen: Con el advenimiento del segundo dualismo pulsional freudiano, viene una serie de cambios en el entendimiento de la sublimación. Esta empieza a presentarse como la causa por excelencia de la desfusión de las pulsiones, lo nos lleva a una paradoja: mientras que la sublimación es la base de cultura, es también 
causa de la destructividad en esa misma cultura. La pulsión de muerte resultante de la desfusión de las pulsiones, a su vez, tendría consecuencias tanto en cada uno de los individuos como en la cultura como un todo, como lo que se observa con respecto a la primacía de la imagen en la sociedad contemporánea. Este artículo busca discutir unos de los efectos de la pulsión de muerte desfusionada, entendida como resultado de la sublimación, principalmente con respecto a la sublimación involucrada en la creación literaria.

Palabras clave: Cultura. Sublimación. pulsión de muerte. Fusión y desfusión pulsional. Creación literaria.

\section{Referências}

Birman, J. (1996). Por uma estilística da existência. São Paulo: Editora 34.

Birman, J. (1997). Desamparo, horror e sublimação. In J. Birman, Estilo e modernidade em psicanálise (pp. 71-102). São Paulo: Editora 34.

Birman, J. (1999). Mal-estar na atualidade - a psicanálise e as novas formas de subjetivação. Rio de Janeiro: Civilização Brasileira.

Carvalho, A. C. (1997). Escrita: remédio ou veneno? Revista Percurso, 18(1), 79-86.

Carvalho, A. C. (2001). Pulsão e simbolização: limites da escrita. In G. Bartucci (Org.), Psicanálise, literatura e estéticas de subjetivação. Rio de Janeiro: Imago

Castiel, S.V. (2007). Sublimação: clínica e metapsicologia. São Paulo: Escuta.

Freud, S. (1980). Luto e melancolia. In S. Freud, Edição standard brasileira das obras psicológicas completas de Sigmund Freud (J. Salomão, trad., Vol. 14, pp. 271-291). Rio de Janeiro: Imago. (Trabalho original publicado em 1917)

Freud, S. (1980). Além do princípio de prazer. In S. Freud, Edição standard brasileira das obras psicológicas completas de Sigmund Freud (J. Salomão, trad., Vol. 18, pp.13-85). Rio de Janeiro: Imago. (Trabalho original publicado em 1920)

Freud, S. (1980). Dois verbetes de enciclopédia. A teoria da libido. In S. Freud, Edição standard brasileira das obras psicológicas completas de Sigmund Freud (J. Salomão, trad., Vol. 18, pp. 285-312). Rio de Janeiro: Imago. (Trabalho original publicado em 1923a) 
Freud, S. (1980). O ego e o id. In S. Freud, Edição standard brasileira das obras psicológicas completas de Sigmund Freud (J. Salomão, trad., Vol. 19, pp. 13-83). Rio de Janeiro: Imago. (Trabalho original publicado em 1923b)

Freud, S. (1980). O problema econômico do masoquismo. In S. Freud, Edição standard brasileira das obras psicológicas completas de Sigmund Freud (J. Salomão, trad., Vol. 19, pp. 197-212). Rio de Janeiro: Imago. (Trabalho original publicado em 1924)

Freud, S. (1980). A negativa. In S. Freud, Edição standard brasileira das obras psicológicas completas de Sigmund Freud (J. Salomão, trad., Vol. 19, pp. 293-300). Rio de Janeiro: Imago. (Trabalho original publicado em 1925)

Freud, S. (1980). O mal-estar na civilização. In S. Freud, Edição standard brasileira das obras psicológicas completas de Sigmund Freud (J. Salomão, trad., Vol. 21, pp. 75171). Rio de Janeiro: Imago. (Trabalho original publicado em 1930)

Freud, S. (2003). El yo y el ello. In S. Freud, Obras completas (J. L. Etcheverry, trad., 2a ed., Vol. 19, pp. 1-59). Buenos Aires: Amorrortu. (Trabalho original publicado em 1923)

Jones, E. (1989). A vida e a obra de Sigmund Freud. (Vol. 3), Rio de Janeiro: Imago.

Kupermann, D. (2003). Ousar rir: humor, criação e psicanálise. Rio de Janeiro: Civilização Brasileira.

Monzani, L. R. (1989). Freud - o movimento de um pensamento (2a ed.). Campinas, SP: Ed. da UNICAMP.

Silva Júnior, N. (1995). Um estado de alma é uma paisagem. Revista Percurso, (15), 2634.

Silva Júnior., N. (2001). A ficcionalidade da psicanálise. Hipótese a partir do inquietante em Fernando Pessoa In G. Bartucci (Org.), Psicanálise, literatura e estéticas de subjetivação (pp. 289-320). Rio de Janeiro: Imago.

Silva Júnior., N. (2003). A sublimação na contemporaneidade: o imperialismo da imagem e os novos destinos pulsionais. Revista Psychê, 7(11), 29-38.

Silva Júnior., N. (2006). A gramática pós-moderna da perversão e sua clínica psicanalítica In F. Milnitzky (Org.), Desafios da clínica psicanalítica na atualidade (pp. 103-115). Goiânia: Dimensão.

Silva Júnior. N. (2010). O masoquismo em tempos modernos. Revista Cult, 13(144), 6062. 
Clarissa Metzger, Psicanalista, mestre em Psicologia Social pelo Departamento de Psicologia Social e do Trabalho do Instituto de Psicologia da Universidade de São Paulo e doutoranda em Psicologia Clínica pelo Departamento de Psicologia Clínica do Instituto de Psicologia da Universidade de São Paulo. Endereço para correspondência: Rua Senador Cesar Lacerda Vergueiro, 199, Vila Madalena, CEP 05435-060, São Paulo, SP.Endereço eletrônico: clarissa2007@uol.com.br

Nelson da Silva Junior, Psicanalista, Doutor pela Universidade Paris VII, Professor Livre Docente do Departamento de Psicologia Social e do Trabalho do Instituto de Psicologia da Universidade de São Paulo, Professor Visitante da Université de Bretagne Occidentale, Professor do Curso de Psicanálise do Instituto Sedes Sapientiae, Membro do Departamento de Psicanálise do Instituto Sedes Sapientiae e da Associação Universitária de Pesquisa em Psicopatologia Fundamental. Endereço para correspondência: Alameda Iraé, 620, conj. 16. CEP: 04075-000, São Paulo, SP. Endereço eletrônico:nesj@terra.com.br 